\title{
Research Progress of Nitrogen and Phosphorus Removal in Municipal Sewage
}

\author{
Liquan Lu ${ }^{1, a}$, Liping Qiu ${ }^{1, b^{*}}$, Shoubin Zhang ${ }^{1, c}$, Jiabin Wang ${ }^{1, d}$, Kang Xie ${ }^{1, e}$
}

${ }^{1}$ School of Civil Engineering and Architecture , University of Jinan , Jinan 250022 , China

a24lu.liquan@163.com, llipingqiu@163.com, ${ }^{\mathrm{c}}$ cea_zhangsb@ujn.edu.cn,

dcea_wangjb@ujn.edu.cn, ${ }^{\mathrm{e}} \mathrm{cea} \_x i e k @ u j n . e d u . c n$

${ }^{*}$ Corresponding Author

Keywords: sewage treatment; denitrification ; phosphorus removal; technology; outlook

Abstract. This paper reviews the status and progress of biological denitrification and phosphorus removal. The mechanism of denitrification and phosphorus removal is analyzed briefly, and the characteristic of some denitrification and phosphorus removal process is also compared. The new process and new technology which is not high popularity are introduced. Finally, the outlook of the future research is put forward in the paper.

\section{Introduction}

Eutrophication is not only directly affect the health of human survival and the sustainable development of the related economic, but also restricted the feasibility of the use of water resources. The value of the sewage treatment plant as point source for denitrification and phosphorus removal of waste water treatment is an effective way to prevent eutrophication. In recent years, our country's urban sewage treatment emission standards are increasingly stringent ${ }^{[1]}$.Therefore, the mechanism and practice of the removal of nitrogen and phosphorus in wastewater are deeply explored, and further improve the effluent quality of the wastewater treatment plant, which has a guide and reference for the development of technology and human health.

\section{The mechanism of biological denitrification and phosphorus removal}

The mechanism of biological denitrification

According to the traditional theory of denitrification, biological nitrogen removal is composed of two processes: the nitrification bacteria in aerobic conditions complete nitrification and denitrification; denitrification bacteria complete denitrification under the anoxic conditions. However, several recent studies showed ${ }^{[2]}$ that Biological removal of nitrogen in the process appeared some new phenomena, beyond people's traditional understanding, for example, nitrification process can't only carried out by autotrophic bacteria, heterotrophic bacteria can also involved in nitrification; some microorganisms can also be involved in denitrification under aerobic conditions. In the case of traditional technology is difficult to meet the existing water quality standards, the emergence of the new theory and new technology is bound to be the future research and promotion of the direction.

The mechanism of biological phosphorus removal

The traditional biological phosphorus removal mechanism includes two processes: release 
phosphorus under anaerobic conditions and uptake phosphorus under aerobic conditions.In 1977, The rapid absorption of phosphorus was first observed by Osborn and Nickholls in the denitrification process, since then, the technology of Denitrifying Phosphorus Removal has gradually attracted people's attention, and has been developed rapidly. Studies suggest that DPB (Denitrifying Phosphorus Bacteria) can utilize with nitrate instead of dissolved oxygen as electron acceptor to uptake phosphorus under anoxic conditions, at the same time, it reduct nitrate to $\mathrm{N}_{2}$ and nitrides, two processes of the denitrification and phosphorus removal are combined, a carbon can achieve two purpose. At present, some of the denitrification phosphorus removal process has been applied in practical engineering in some European and American countries, and has achieved good effects of nitrogen and phosphorus removal. At home, we made some progress and preliminary results on the denitrification phosphorus removal, but we still need a lot of research and debugging to put into production ${ }^{[3]}$. Although the process has not been widely used in China, its advantages in biological phosphorus removal will promote the development of the field of phosphorus removal.

\section{Technology of biological denitrification and phosphorus removal}

Technology of biological denitrification

The technology of wastewater biological denitrification is to change aerobic / anoxic environment by the reactor and personal control to achieve the purpose of nitrification and denitrification. According to the different sewage treatment process, the technology of biological denitrification was divided into the activated sludge process and biofilm denitrification process.

Activated sludge denitrification process

The technology of activated sludge denitrification is the normal terms of biological wastewater treatment. At present, the engineering application of a wide range of biological denitrification process has $\mathrm{A} / \mathrm{O}$ and $\mathrm{A}^{2} / \mathrm{O}$, UCT, MUCT, VIP, Bardenpho technology, Phoredox (modified Bardenpho process), BICT, SBR, oxidation ditch process and so on.

$\mathrm{A} / \mathrm{O}$ process set up the anaerobic and aerobic area to achieve the purpose of removal of organic matter and nitrogen. $\mathrm{A}^{2} / \mathrm{O}$ as the simple simultaneous nitrogen and phosphorus removal process is widely used in domestic and foreign large urban sewage treatment plants. UCT, MUCT, VIP other processes are the improved form of $\mathrm{A}^{2} / \mathrm{O}$ process, these process change the sludge and mixed liquid backflow to reduce the adverse effects to a certain extent. The BICT is presented by Huang in 2003, which is based on that the autotrophic nitrifying bacteria and denitrifying bacteria are cultivated without heterotrophic ${ }^{[4]}$. Typical SBR treatment system is divided into 5 stages: water, reaction, precipitation, drainage and idle, the basic operation mode in the removal of organic matter can achieve a more satisfactory treatment effect.

The traditional activated sludge process has been infiltrated into the sewage treatment plant of each scale, also has accumulated a lot of experience in engineering practice, but there are still many contradictions and problems. Understanding the mechanism of nitrogen removal and creating a more advanced technology will be one direction of the application in activated sludge process.

Biofilm denitrification process

Biofilm denitrification process has been paid attention to some researchers by its unique advantage. Biofilter, biological rotating contactor, biological aerated filter, submerged biofilter and biological fluidized bed technology has been researched and Applicated . In recent years, some domestic experts are more in-depth research, the content involves the development and improvement of biofilm carrier, fixed mechanism and technology on the surface of the carrier, the growth of biofilm, the organic matter removal and so on. Qiu et al are devoted to the research of Biological Aerated 
Filter (BAF), discuss deeply the characteristics of biofilm population of BAF, and obtain the good effect of denitrification and phosphorus removal by improving the Filter material which uses the modified steel slag composite filter material collaborative alternation of A/O-BAF operation ${ }^{[5]}$; Chen et al ${ }^{[6]}$ using mesh biological rotating contactor to do experimental study of sewage, in the first level COD load at about $156.18 \mathrm{~g} /\left(\mathrm{m}^{2} \cdot \mathrm{d}\right)$, ammonia nitrogen removal rate can reach $80 \%$.

Study on the biofilm reactor will tend to further explore the immobilization mechanism of microorganisms in the surface of the carrier, develop microorganism immobilization technology which is widely applicable in practical engineering, further improve the purification function of the various biological membrane reactor, in-depth study biofilm microbial growth ,substrate removal kinetics and energy metabolism of biofilm microbial. At the same time, the biofilm denitrification process will further develop in the direction of energy saving and automation control.

New technology of biological denitrification

Besides the traditional nitrogen removal process, research on new technology in recent years can be endless. The new type of nitrogen removal process is mainly based on the research of nitrite nitrogen. Some invented the shortcut nitrification-denitrification and oxidation of anaerobic ammonia, found that the phenomenon of simultaneous nitrification and denitrification. Researchers have developed many new technologies, such as Sharon process, Anammox process and OLAND process.

Helling et al in Netherlands developed a new process called Sharon which is based on shortcut nitrification and denitrification in $1997^{[7]}$, this process uses the difference of growth rate of nitrite and nitrate bacteria under different conditions such as temperature, $\mathrm{pH}$, dissolved oxygen and hydraulic retention time to achieve shortcut nitrification and denitrification. Also in the Netherlands, Kluyver who are from the technical university of Delft biotechnology laboratory developed anaerobic ammonia oxidation process in $1990^{[8]}$. OLAND is a new type of biological nitrogen removal process, which is combined limiting oxygen to achieve nitrozation with anaerobic ammonium oxidation. Simultaneous nitrification and denitrification(SND) refers to existing nitrification and denitrification in a reactor to achieve denitrification. Peng ${ }^{[10]}$ confirmed that the SND could get the good effect of nitrogen and phosphorus removal of sewage in the pilot oxidation ditch process tests, Feng ${ }^{[10]}$ et al discovered a significant simultaneous nitrification and denitrification when using SBR process to dispose monosodium glutamate wastewater.

Biological phosphorus removal technology

Biological phosphorus removal technology came from the phenomenon of excessive P-absorbing in 1960s by Srinath. Through decades of research and development, biological phosphorus removal technology has risen from theory research to production practice. $\mathrm{A}^{2} / \mathrm{O}, \mathrm{SBR}$, oxidation ditch, UCT, MUCT, PhoStrip and so on are the effective process to removal phosphorus. Nowadays, enhanced biological phosphorus removal (EBPR) is considered to be a more economic, sustainable typical biological phosphorus removal process ${ }^{[11]}$. The future development of the field is to improve the understanding of the metabolism mechanism of PAOs(Polyphosphate accumulating organisms), GAOs(Glucose accumulating organisms) and filamentous bacteria, so as to better grasp the practical control strategy to improve the PAOs advantage.

Technology of simultaneous nitrogen and phosphorus removal

From the above, it's not difficult to see that there is no clear boundary between the nitrogen removal process and phosphorus removal process from a certain point of view. In today's engineering practice, there are many processes can achieve the effect of nitrogen and phosphorus removal in the same time. 
Combination denitrification and phosphorus removal process

Nowadays, a process may not be enough to meet the requirements of the water quality standards, the combination process came into being. Some combination technology has some research results. For example, BAF- $\mathrm{A}^{2} / \mathrm{O}$ combination process, SBR-AOA nitrogen and phosphorus removal process, MSBR (combination of SBR and $\mathrm{A}^{2} / \mathrm{O}$ Technology), SBR-ABR combination process, SBBR process, MBR combination process and so on.

Chen ${ }^{[12]}$ uses continuous flow double sludge $\mathrm{A}^{2}$ / O - BAF system to deal with real life sewage and proves that the BAF can strengthen the effect of nitrogen and phosphorus; MSBR process is developed in the early $1980 \mathrm{~s}$, it is combined by $\mathrm{A}^{2} / \mathrm{O}$ process and SBR process in series, saves a lot of valves and increases the return sludge system; Hu et al ${ }^{[13]}$ used ABR - SBR combined process system to deal with restaurant wastewater and studied the effect and the best operating conditions by this process in the low temperature condition of winter treatment, ammonia $\left(\mathrm{NH}_{3}-\mathrm{N}\right)$ and total nitrogen (TN), total phosphorus (TP) removal rate reached $92 \%, 85 \%$ and $75 \%$;SBBR process is a new type of the biological membrane method in sequencing batch, has been applied in the treatment of leather wastewater ${ }^{[14]}$, high nitrogen pickle production process of high salt waste water and waste leachate.

\section{Conclusion}

This paper gives a brief overview of the process of biological nitrogen and phosphorus removal, and discuss the research direction in this field. In recent years, in addition to the new sewage treatment plant to solve the problem of water eutrophication, the new technology of not to expand the volume of the existing sewage treatment plant also significantly increased. No matter choose single biological denitrification, biological phosphorus removal technology, simultaneous denitrification and phosphorus removal technology or new process, according to the specific factors to choose the appropriate method is the key to solve the present problems under the special conditions.

\section{Acknowledgements}

This work was partly supported by National Natural Science Foundation of China(51278225), Science and technology development projects of Shandong province(2013GSF11704), Shandong Provincial Natural Science Foundation, China(ZR2013EEQ007 , ZR2015EM021) and Science and technology development projects of Jinan(201302079).

\section{References}

[1] Q.Ding and Z.X.Wang: Environmental Science and Technology Vol.23(2010), p.89.

[2] R.Y.Bai: New Technology, New Technology and Equipment in Water Treatment(Chemical Industry Publications, China 2012).

[3]D.Zhang and L.Hu: Guangzhou Chemical Industry Vol.12(2010), p.207.

[4]Y.Huang and Y.Li: Water Treatment Technology Vol.5(2011), p.103.

[5]L.P.Qiu and J.Ma: China Environmental Science Vol.25(2010), p.214.

[6]Q.Chen and F.Li: Journal of Harbin Institute of Technology Vol.12(2006), p.2077. 
[7]X.L.Wang and Y.Z.Peng: The Technology and Application of $A^{2} / O$ in Sewage Biological Denitrification and Phosphorus Removal(Science Publications, China 2009).

[8]M. Ali and S. Okabe: Chemosphere Vol.141(2015), p.144.

[9] Y.Z.Peng: Journal of Environmental Sciences Vol.20(2008), p.398.

[10]H.Feng and H.J.Xu: China Water \& Wastewater Vol.24(2008), p.51.

[11] L.P.Qiu, G.W.Wang and S.B.Zhang: Environmental Pollution \& Control Vol.32(2010), p.66.

[12]J.L.Xiao and T.Hu: Guide of Sci-tech Magazine Vol.26(2008), p.31.

[13]Z.Q.Hu and Y.Chu: Water Treatment Technology Vol.3(2011), p.72.

[14] C.D. Iaconi and A. LOPEZ : Environment Science\&Technology Vol.37(2003), p.3199. 